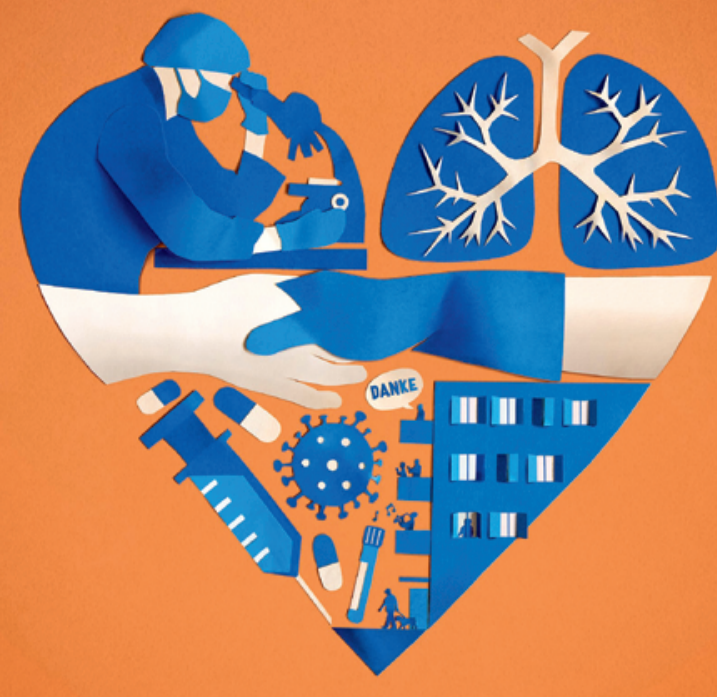

\title{
Philanthropie in der Pandemie
}

\section{Corinna Adler}

Geschäftsführerin USZ Foundation (Stiftung des Universitätsspitals Zürich)

Wie können wir das Universitätsspital Zürich in der Coronapandemie unterstützen? Mit dieser Frage wandten sich zahlreiche Menschen im Frühling 2020 an die USZ Foundation. Damit war die Idee geboren für den Corona-Solidaritätsfonds. Er hilft, die Mitarbeitenden zu entlasten, die Betreuung der Patientinnen und Patienten zu verbessern und Forschung zu finanzieren. Ein Rückblick auf ein bewegtes Jahr der Solidarität.

Manchmal fehlten uns im vergangenen Jahr einfach die Worte. Zum Beispiel, als wir die E-Mail einer Krebspatientin erhielten, die vom Corona-Solidaritätsfonds des Universitätsspitals Zürich (USZ) erfahren hatte. Sie lebe in bescheidenen Verhältnissen und möchte fragen, ob eine Spende von 20 Franken auch in Ordnung sei. Ob dieser Geste der Solidarität kann man nur innehalten und dankbar sein.

Es sind zahlreiche solche Geschichten, die wir seit Beginn der Pandemie erleben durften. Gegründet wurde die USZ Foundation 2017 mit dem Ziel, medizinische Innovationen am USZ zu fördern, die als neue Behandlungen baldmöglichst den Patientinnen und Patienten zugutekommen. Die Solidarität mit erkrankten Menschen macht unsere Tätigkeit erst möglich. Corona hat dieses Gemeinschaftliche auf eine neue Stufe gehoben.

\section{Kooperation wie nie zuvor}

Dies zeigte sich etwa daran, dass Wissenschaftlerinnen und Wissenschaftler über alle Grenzen hinweg ihr Wissen zu Corona austauschten wie nie zuvor. Nur so war es möglich, derart schnell das Erbgut des Virus zu entschlüsseln, Behandlungen klinisch zu testen und Impfstoffe zu entwickeln.

Spitäler waren und sind von der Pandemie ganz speziell betroffen. War in der ersten Welle vor allem die Beschaffung von Schutzmaterial die grosse Herausforderung, war es im weiteren Verlauf vor allem der enorme Arbeitseinsatz der Mitarbeitenden, der bis an die Grenzen der Belastbarkeit ging. Das Universitätsspital Zürich passte sich der Situation ständig an, vom Materialeinkauf bis zur Eröffnung zusätzlicher Bettenund Intensivstationen. 
Gerade einem universitären Spital kommt in der aktuellen Situation eine besondere Bedeutung zu, da es die am schwersten Erkrankten aufnimmt. Gleichzeitig haben USZ-Mitarbeitende rund 30 Forschungsprojekte gestartet, um Covid-19 besser verstehen und behandeln zu können.

\section{Unterstützung von allen Seiten}

Die derzeitige Situation zeigt uns so deutlich wie kaum je zuvor, wie wichtig es ist, neue medizinische Behandlungen so rasch wie möglich zu entwickeln. Möglich wird dies, wenn alle Akteure zusammenspannen - von internationalen Organisationen wie der WHO über Staaten und Unternehmen bis zu Stiftungen und uns allen als Bürgerinnen und Bürgern.

Diese Solidarität durfte das USZ in grossem Ausmass spüren - zum Beispiel aus dem Gesundheitswesen selber. Pensionierte oder aus dem Beruf ausgestiegene Gesundheitsfachpersonen meldeten sich für eine temporäre Mitarbeit. Angehörige verschiedener Kliniken innerhalb des Spitals halfen einander aus. Zürcher Medizinstudierende starteten eine Plattform für Einsätze am Spital - eine Initiative, an der bis heute Hunderte von Studierenden teilnahmen und die bald auch in anderen Städten schule machte.

\section{Die Idee für einen Fonds}

Auch in der Gesamtgesellschaft war die Solidarität gross. Applaus von den Balkonen und «Danke»-Plakate im Spitalpark waren nur der Beginn davon. Die Bevölkerung wollte das USZ auch materiell unterstützen von selbstgebackenen Kuchen zur Pausenstärkung bis zu Schenkungen von Masken seitens mehrerer Unternehmen.

Auch bei unserer Stiftung erkundigten sich im Frühling 2020 zahlreiche Menschen, wie sie dem Spital helfen könnten. Deshalb haben wir den Corona-Solidaritätsfonds USZ gegründet. Sein Ziel zeigte sich bald sehr klar: Die Mitarbeitenden entlasten, die Behandlung von Covid-19-Betroffenen verbessern und Forschung zum Coronavirus ermöglichen. Ein zentrales Anliegen war und ist es, Überforderung bei den Mitarbeitenden zu verhindern und ihre Gesundheit zu schützen. Dies sowohl durch zusätzliche Mitarbeitende wie auch Beratung und Burnout-Prävention. Dabei gingen die Bestrebungen des USZ über das eigene Spital hinaus, indem etwa in einem Projekt ein Beratungsinstrument entwickelt wurde, das Gesundheitsfachpersonen hilft, Stress und Sorgen während einer Pandemie zu bewältigen.

Die Spitaldirektion entscheidet unbürokratisch und rasch, wo die Mittel aus dem Solidaritätsfonds am dringendsten benötigt werden. Seitens der Mitarbei-

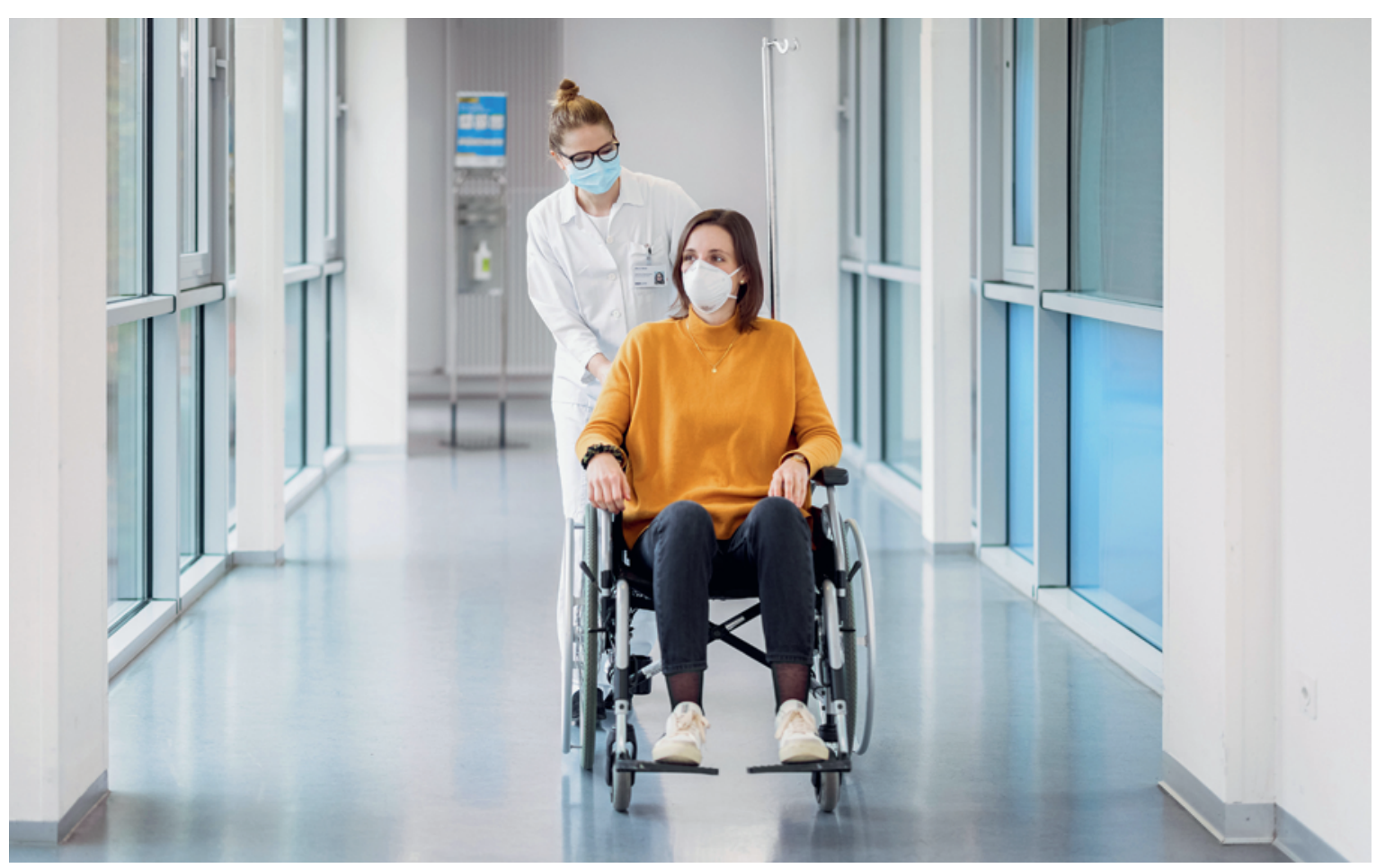

Medizinstudierende unterstützen Spitäler während der Pandemie bei der Bewältigung zusätzlicher Aufgaben, so auch am Universitätsspital Zürich. 
tenden wurden dazu laufend neue Ideen eingereicht und geprüft. Bis heute durften wir rund eine Million Franken an Schenkungen für den Solidaritätsfonds entgegennehmen und konnten damit zahlreiche Projekte unterstützen (vgl. Kasten). Es sind dies alles Projekte, die am USZ über die reguläre Versorgung hinaus wichtige «Freiräume» ermöglichen - gerade wenn es um die Entlastung der Mitarbeitenden, Zeit für das Zwischenmenschliche oder um die Beschleunigung der Forschung geht.

\section{Kreative Solidarität}

Die Vielfalt und Kreativität der Solidarität mit dem USZ hat uns sehr berührt und beeindruckt. Menschen aus den unterschiedlichsten Lebenssituationen haben das USZ in verschiedensten Formen beschenkt. So organisierte ein Gönner einen virtuellen Sponsorenlauf, um die Mitarbeitenden des USZ mit Restaurantgutscheinen zu beschenken - und damit gleichzeitig die darbende Gastronomie zu unterstützen. Die Leiterin eines Coiffeurgeschäfts wollte sich dafür bedanken, dass ihre an Covid-19 erkrankten Eltern am USZ gut betreut wurden, und schenkte den Spitalmitarbeitenden Coiffure-Gutscheine. Sehr berührt hat uns auch die Aktion einer Zürcherin, die mit drei Freundinnen in ihrem
Bekanntenkreis einen Spendenaufruf zugunsten der Intensivpflege-Mitarbeitenden lancierte. Die über WhatsApp verbreitete Idee stiess auf so viel Resonanz, dass das angegebene Twint-Konto mehrere Tage überlastet war.

\section{Zusammenrücken in der Krise}

Krisen können uns Menschen an die Grenzen des Aushaltbaren bringen. Niemand hat die Covid-19-Pandemie vorausgesehen, und wir alle hoffen, sie möge so rasch wie möglich und in allen Teilen der Welt enden. Krisen können aber auch das Gute stärken und die Menschen näher zusammenrücken lassen. Unsere Stiftung durfte dies seit dem Frühling 2020 eindrücklich erleben.

Die Pandemie zeigt eindringlich, dass unsere Gesundheit das wertvollste Gut des Menschen ist. Um sie zu schützen, brauchen wir ein starkes Gesundheitswesen und engagierte Menschen, die sich in der medizinischen Forschung rasch neuen Herausforderungen widmen.

Schon vor Corona durfte unsere Stiftung immer wieder Schenkungen von ehemaligen Patientinnen und Patienten des USZ entgegennehmen, die ihre Dankbarkeit für eine Behandlung ausdrücken wollten. In der aktuellen Situation wird uns allen die Fragilität unserer Gesundheit schlagartig bewusst, was sich in der Solidarität der ganzen Bevölkerung etwa mit Spitälern und der Forschung zeigt. Mögen diese Unterstützung für kranke Menschen und die Wertschätzung für die Arbeit der Gesundheitsfachpersonen uns weit über die Pandemie hinaus begleiten. Denn es gibt noch viele leidende Menschen - und viele Forschende mit guten Ideen, wie man dieses Leid dank medizinischen Innovationen lindern könnte. Die öffentliche Finanzierung stellt die medizinische Grundversorgung sicher und ermöglicht insbesondere die Grundlagenforschung. Philanthropie kann darüber hinaus helfen, noch mehr innovative Ideen für neue Behandlungen möglichst rasch umzusetzen.

\section{Mehr zum Corona-Solidaritätsfonds USZ auf www.usz-foundation.com}

Bildnachweis

Illustration: USZ Foundation/Illustration: Isabelle Bühler Foto: USZ Foundation/ Nicolas Zonvi 